\title{
A study in the relationship between greenery of urban parks and bird diversity in Tainan City, Taiwan
}

\author{
H.-T. Lin, C.-Y. Sun \& C.-T. Hung \\ Department of Architecture, National Cheng Kung University, Taiwan
}

\begin{abstract}
Green space is important for the maintenance of the ecological dimension of a sustainable urban landscape. Therefore, in order to figure out the relationship between the greening of urban parks and bird diversity, we used 5 avian ecological diversity indexes, such as Species richness, Abundance, ShannonWeiner diversity index, Evenness, and Margalef's richness indices, to evaluate the functionality of different types of urban parks. Therefore, birds in 17 parks were surveyed with the circular-plot method from August of 2004 to April of 2005; meanwhile, the greening level of urban park of Tainan city in Taiwan was measured by remote sensing method. As the result, overall there was higher bird species richness in higher greening level parks. Our findings emphasize the importance of urban park with abundant greening to maintain high ecological diversity. Thus, we suggest that increasing greening level of urban parks can promote the bird diversity in urban area.
\end{abstract}

Keywords: urban habitat, biodiversity, normalized difference vegetation index.

\section{Introduction}

According to governmental statistics, $77.7 \%$ of the nation's population dwells in urban area which only occupies $12.5 \%$ of the country's area. In order to accommodate such high population density, urban expansion is inevitable. Without appropriate consideration of the ecosystem during urban planning, such expansion will transform natural habitat into all sorts of man-made constructions, thus destroying the urban ecological environment.

Urban habitats differ from natural environments in several aspects. For example, urban areas dwell large amount of population, the traffic impact is 
intense, the microclimate is influenced by urban heat island effect, the planting of decorative lawns and exotic tree species, etc. These environmental change caused by human may play an important role in the urban ecosystem. However, most bird-habitat relationship studies have been made in natural ecosystems, while urban areas were much less focused on (Tilghman (1987); McDonnell et al. [12]). Studies have been implemented to investigate the response of avifauna to urban environment. Some focus on how the avian community responds to local habitat structure or landscape structure of urban parks, woodlands, or wooded streets (Emlen [6]; Tilghman [15]; Fernandez-Juricic et al. [7]). Many of these studies point out that species richness decreases with the degree of urbanization, and that total avian density increases with urbanization (Emlen [6]; Beissenger and Osborne [1]; Blair [2]). In addition, species of different guild respond differently to urbanization (Lim and Sodhi [10]).

Other than the increase of buildings, urbanization also brings about the fragmentation of natural woodland and the decrease of urban green area. However, owing to difficulties of measuring urban green area, few studies focus on the effect of the decrease of urban green area. The development of satellite imagery at various resolutions has generated interest among scientific community regarding the potential of remote sensing to measure and monitor variables that affect biodiversity (Nohr and Jorgensen [13]; Seto et al. [14].

Of the numerous vegetation indices, the normalized difference vegetation index (NDVI), which is defined as (NIR - RED)/(NIR + RED), where NIR and RED represents surface reflectance in the red and near infrared region of the spectrum, has been the most widely used index in global vegetation studies. High positive value of NDVI corresponds to dense vegetation cover, whereas negative values are usually associated with bare soil, snow, clouds or non-vegetated surfaces. The NDVI has been empirically shown to relate strongly to vegetation seasonal dynamics, leaf area index measurement, green vegetation cover and biomass estimation (Tucker et al. [16]; Gould [8]).

In this study, we investigate how avian community responds to human activities, park structure, and urban environment. We correlate, through a multivariate method, the environmental factors with the avian community, including overall avian composition, species, and biodiversity indices.

\section{Method}

\subsection{Study area}

This study was conducted in Tainan city $\left(120^{\circ} 11^{\prime} \mathrm{E}, 22^{\circ} 58^{\prime} \mathrm{N}\right)$ in southern Taiwan. Tainan is a city of 749,807 people and covers about $175.64 \mathrm{~km}^{2}$. The average population density is 4,269 people $/ \mathrm{km}^{2}$, and the average population density in the main areas of the city varied between 14,000 and 15,500. The average temperature throughout the year is $24.4^{\circ} \mathrm{C}$, and the mean annual precipitation is $1347.7 \mathrm{~mm}$. With such high population density, however, the total park area in Tainan is $1.76 \mathrm{~km}^{2}$, which is approximately $1 \%$ of the city's area. This indicates that Tainan is an over-developed, highly-urbanized city. In 
such over-developed city, bird census is conducted in highly-vegetated area lest we count no birds. Therefore, the bird census was conducted in urban parks.

17 parks, ranging from 0.6 to 14.3 ha, with the total area of $635,197 \mathrm{~m}^{2}$ were selected as the samples of this study. All parks that are larger than 1 ha in Tainan were all included in this study. In order to increase the sample size, 2 other parks that are smaller than 1 ha were also selected. The reason for choosing these two parks is that, according to previous study, they had relatively high species richness, thus made it more suitable for this study than other small parks.

\subsection{Avian assemblage surveys}

Birds in 17 parks were surveyed with circular-plot method from August, 2004 to April, 2005. Bird censuses were conducted twice every season, in other words, 8 censuses were conducted for every park. Censuses last 8 min per point, and were conducted within three hours after sunrise (approximately 6-9 a.m.), in good weather only. All surveys were conducted by the same person. Birds flying over the canopy were not included. Scientific names and the individuals counted of the birds were included in Appendix A.

10 to $15 \%$ of the park area was selected as the survey area. Since the radius of census point is $15 \mathrm{~m}$, we place one census point for every 0.7 ha of park area. A total of 78 points were established in 17 parks. Census points were placed $50 \mathrm{~m}$ apart to reduce the possibility of double counting. They were also placed at least $25 \mathrm{~m}$ away from the edge of the park to avoid traffic disturbance. Species abundance was calculated for each park as the sum of the number of individuals recorded from each point divided by the number of census points.

\subsection{Environmental variables measured}

\subsubsection{Environmental variables within the park}

Environmental variables within the park (including park area, edge index, human activity, and vegetation structure) and urban variables (including building area and vegetation area) were measured for each park (Table 1). The formula of the edge index is $D I=P /(2 \sqrt{A \pi})$, where $\mathrm{P}$ is the perimeter of the park and $\mathrm{A}$ is the area. The area and perimeter of the park is derived from GIS map by the Urban Development Bureau. To correctly determine the dynamic human activity is difficult, for different types of activities affects the avian community differently. For example, feeding the bird and jogging in the park have different impacts on birds. Therefore, instead of counting the number of people in the park, we indirectly evaluate human activity by measuring the area of the building and pavement within the park; the increase of these facilities will increase the range of human activity and, at the same time, eliminate the area that can be planted with vegetations, which adversely influence bird survival and reproduction.

Vegetation structure includes measures of the density of trees, foliage height diversity (FHD), and plant species diversity. These vegetation structure variables are determined by a thorough survey of all plants higher than $0.9 \mathrm{~m}$ in height in the park. The presence of the following foliage height intervals: $<0.9 \mathrm{~m}, 0.9-1.5$ $\mathrm{m}, 1.5-3 \mathrm{~m}, 3-5 \mathrm{~m},>5 \mathrm{~m}$, is recorded. The values of each height levels are then 
converted to FHD by using the Shannon-Weiner's diversity index. The plant species diversity is determined by the Simpson's diversity index: $S D I=1-\sum_{i=1}^{S} 1-P i^{2}$, where pi is the proportion of the observations in the $i^{\text {th }}$ category.

Table 1: $\quad$ Variables measured.

\begin{tabular}{ll}
\hline Variable code & Description \\
\hline \hline AREA & area of the park \\
DI & edge index \\
VEGAREA & foliage height diversity \\
FHD & species richness of plants within the park \\
PLANTSPE & Simpson's diversity index of plants within the park \\
PLANTDIV & number of plants per hectare \\
PLANTDEN & percentage of area covered with water (eg. Pond, river) \\
WATER\% & percentage of area covered with pavement \\
PAVEMENT\% & percentage of area covered with building \\
BUILD $\%$ & area covered with buildings within a $500 \mathrm{~m}$ radius range \\
BUILD500 & area covered with buildings within a $1000 \mathrm{~m}$ radius range \\
BUILD1000 & area covered with buildings within a $2000 \mathrm{~m}$ radius range \\
BUILD $2000^{\mathrm{a}}$ & the number of pixels with a NDVI value higher than 0.2 within a $50 * 50$ \\
VEG50 & pixels range \\
the number of pixels with a NDVI value higher than 0.2 within a & $100 * 100$ pixels range \\
VEG100 & the number of pixels with a NDVI value higher than 0.2 within a \\
& $150 * 150$ pixels range \\
VEG150 & the number of pixels with a NDVI value higher than 0.2 within a \\
& $200 * 200$ pixels range \\
VEG $200^{\mathrm{b}}$ & the number of pixels with a NDVI value higher than 0.2 within a \\
& $250 * 250$ pixels range \\
\hline
\end{tabular}

a. the center of the circle coincide with the center of the park.

b. the center of the square coincide with the center of the park.

\subsubsection{Urban environmental variables}

Landscape changes at different scales have the potential to affect different organisms, depending on the range of scales that is relevant to a particular species. Because environmental change at different scales may affect different species, we measure urban environmental variables at several different scales, in order to find out at which scale the avian community respond to.

According to the study of Hostetler and Holling (2000), many bird species were correlated with the amount of tree canopy cover from such broad scales as $0.2-85 \mathrm{~km}^{2}$. But to carry out such large scale study in parks of Tainan city is not practical. The distances between parks are short; therefore, investigating variables beyond the scale of $25 \mathrm{~km}^{2}$, one would come up with similar value of variables. Therefore, the maximum scale adopted in this study is approximately a radius of $2 \mathrm{~km}$ set from the center of the park. 
In this study, we measured two categories of urban environmental variables: building area and vegetation covered area surrounding the park. To assess the degree of urbanization, we measure the building area around the park. At the center of each park, we drew circles of 3 different radiuses: 500, 1000, $2000 \mathrm{~m}$, and measured the area covered with buildings. The information of the building coverage area was derived from the GIS map by the Urban Development Bureau.

NDVI has been related to ground vegetation cover in the past studies (Lillesand et al. [11]). There are some studies that focus on how avian community respond to broad scale vegetation structure, and applied NDVI on their researches (Nohr et al. [13]; Seto et al. [14]). In this study, we counted the number of pixels with a NDVI value higher than 0.2 as an index for vegetation covered area (figure 1). In other words, pixels with NDVI higher than 0.2 is considered as vegetated land, and the more such pixels surrounding the park, the "greener" the environment. The reason of selecting 0.2 as the threshold value is that the NDVI value of soil is between 0.1 0.2 (Carlson and Ripley [3]), other urban ground man-made objects, such as buildings, pavement, have spectral characteristics similar to soil. The satellite image used in this study is based on a Formosat- 2 level 4 product scene. The resolution of the image corresponds to $8 * 8 \mathrm{~m}^{2}$ per pixel. The scene was recorded on 12 July, 2004, and was geometrically corrected.

$\begin{array}{lllll}0.33 & 0.44 & 0.44 & 0.44 & 0.48 \\ 0.34 & 0.37 & 0.38 & 0.38 & 0.39 \\ 0.38 & 0.33 & 0.31 & 0.23 & 0.10 \\ 0.26 & 0.11 & 0.04 & 0.04 & -0.07 \\ 0.08 & 0.06 & 0.03 & -0.04 & -0.03 \\ 0.13 & 0.09 & 0.04 & -0.05 & -0.04 \\ 0.08 & 0.03 & 0.06 & 0.03 & -0.05\end{array}$

In this $6 * 7$ pixels sample, we view the pixels with a NDVI value higher than 0.2 (grey color boxes) as vegetated land, and count the number of such pixels.

Figure 1: An example of measuring the vegetation covered area.

\subsection{Data analysis}

Multivariate analyses were undertaken using PRIMER V.5.0 (Clarke and Gorley [4]) to assess overall changes in avian composition. Non-metric multidimensional scaling (MDS) was used to indicate the similarity of avian composition among parks. These were iterated at least 10 different starting values to ensure that a global optimum was achieved (indicated by no decline in the stress value) (Clarke and Gorley [4]). A log-transform was used on the species abundance data to give an equal weighting to common and rare species (Clarke and Warwick [5]). The BIOENV procedure in PRIMER was used to examine the relationships between avian community and environmental factors (Clarke and Gorley [4]). In the BIOENV procedure the among-site species similarity matrix was constructed only once, whereas the environmental matrix was computed for every possible combination of environmental variables. 
Spearman's rank correlation coefficients $(\mathrm{Pw})$ were calculated for the every match between the species matrix and each of the possible environmental matrices. The set of variables that has the highest $\mathrm{Pw}$-value is that best explain the species data (Clarke and Gorley [4]).

For species richness, abundance, diversity, we employed stepwise multiple regression method to examine their relationship with environmental variables. Considering the high auto-correlation between the environmental factors, we performed a correlation analysis to eliminate variables that highly correlate $(\mathrm{R}>0.85)$. The correlation matrix is shown as table 2 . The different scales of urban variables (BUILD500, 1000, 2000, and VEG50, 100, 150, 200, 250) highly correlate to each other, thus when proceeding statistical analysis, it is difficult to ascertain a particular scale that avian species respond to. We select the BUILD2000 and VEG50, VEG100, VEG250 as the final urban environmental factors. As a result, 12 factors were selected from the analysis. Only these factors are then put in the statistic analysis: AREA, DI, FHD, PLANTDIV, PLANTDEN, WATER\%, PAVEMENT\%, BUILD\%, BUILD2000, VEG50, VEG100, VEG250.

Table 2: $\quad$ Correlation matrix of environmental variables.

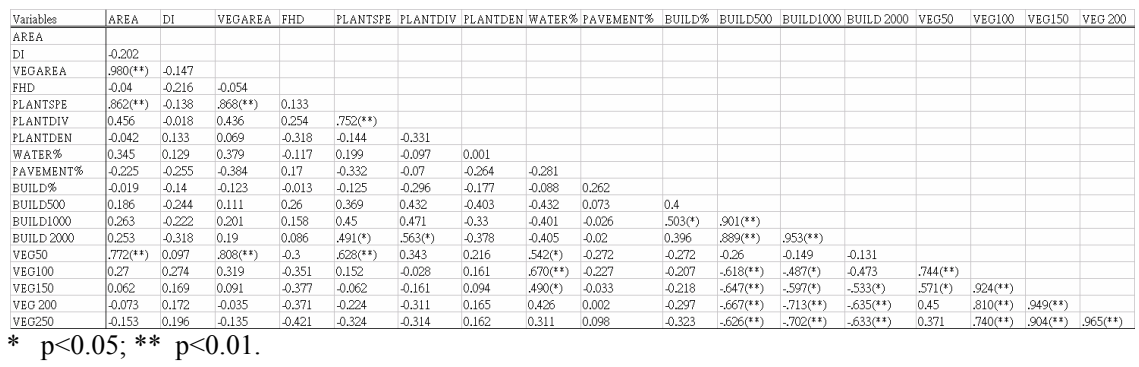

\section{Results}

\subsection{Community composition}

A total of 5970 bird records, comprising 29 species were obtained from the 17 parks during the survey period (Appendix A). Of the 29 species recorded, 26 are breeding birds, 3 are migratory. Of the 26 breeding birds, 6 are water birds (including the two unidentified species). 9 species occurred in only one park, and 4 species were recorded in all 17 parks. Only 13 species were observed in more than 5 different parks or more (Appendix A). The average bird species per park is $11.4(\mathrm{SD}=3.4)$, and 135.98 birds/ha were counted in all parks $(\mathrm{SD}=45.15)$. The abundance of each species varied among parks. The most common species are eurasian tree sparrow, light-vented bulbul, japanese white-eye, they were found in every park, and was accounted for $22.66 \%, 32.50 \%$, and $24.57 \%$ of the total bird abundance respectively. The three species take up $79.73 \%$ of the total bird abundance. Besides the three species, pacific swallow also occurred in all parks, and accounted for $3.28 \%$ of the total abundance. 
Table 3: $\quad$ Result of BIOENV analysis used to test the greatest contribution to differences in the avian community of 17 parks.

\begin{tabular}{cccc}
\hline No. & number of variables & $\mathrm{Pw}$ & selections \\
\hline \hline 1 & 2 & 0.571 & 9.12 \\
2 & 3 & 0.558 & $3,9,12$ \\
3 & 3 & 0.549 & $4,9,12$ \\
4 & 3 & 0.545 & $2,9,12$ \\
5 & 4 & 0.537 & $3,4,9,12$ \\
6 & 4 & 0.534 & $3,5,9,12$ \\
7 & 5 & 0.533 & $3,4,5,9,12$ \\
8 & 4 & 0.523 & $4,5,9,12$ \\
9 & 4 & 0.522 & $2,4,9,12$ \\
10 & 4 & 0.522 & $2,3,9,12$ \\
\hline 1=AREA, 2=DI, 3=FHD, 4=PLANTDIV, 5=PLANTDEN, 6=WATER $\%, 7=$ PAVEMENT\%,
\end{tabular}

1=AREA， 2=DI， 3=FHD， 4=PLANTDIV， 5=PLANTDEN， 6=WATER\%， 7=PAVEMENT\%, $8=\mathrm{BUILD} \%$, 9=BUILD2000, 10=VEG50, 11=VEG100, 12=VEG250.

Table 4: $\quad$ Multiple regression model for avian species and abundance. The abbreviation of each variable is given in Table 1 .

\begin{tabular}{lccc}
\multicolumn{1}{c}{ Biodiversity indices } & \multicolumn{1}{c}{ Regression model } & Adj_R & P \\
\hline \hline species richness & 5.907E-05 * AREA + 22.999* WATER\% $\%$ +8.361 & 0.808 & $<0.001$ \\
species abundance & $1.487 \mathrm{E}-05 *$ BUILD2000 + 81.128 & 0.233 & 0.029 \\
\hline
\end{tabular}
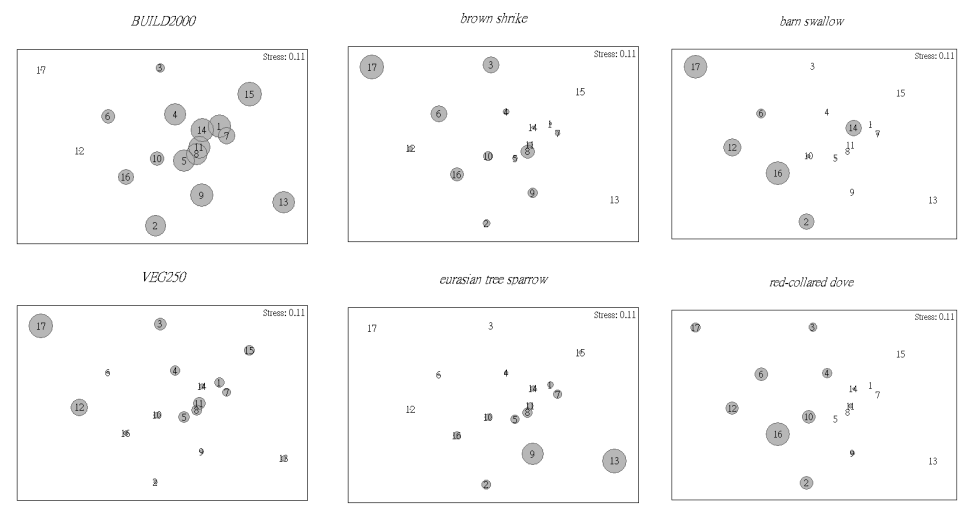

The number in the plot indicates the park number, and the size of the bubble indicates the value of each variable.

Figure 2: $\quad$ MDS plots of avian composition in 17 parks of Tainan City and their relationships with environmental factors and avian species.

\subsection{Responses of avian assemblage to environmental changes}

\subsubsection{Environmental variables that affect the avian composition}

The MDS plot of avian composition in 17 parks is shown in figure 2 . The distance between park 13 and 17 is the furthest, which implies that the avian compositions of the two parks have the lowest similarity. As can be seen, brown 
shrike is most abundant in park 17 , and least abundant in park 13 . Whereas rock pigeon and eurasian tree sparrow show an opposite trend to brown shrike. Spearman's rank correlation coefficients $(\mathrm{Pw})$ of 10 variables have been calculated in the BIOENV procedure (table 3). Result number 1, which include building area (at $\mathrm{R}=2000 \mathrm{~m}$ scale) and vegetation covered area (at $250 * 250$ pixels scale) surrounding the park, best explain the overall pattern in avian composition: $(\mathrm{Pw}=0.571)$. The abundance of brown shrike, barn swallow, and red-collared dove correlated negatively with BUILD2000, and eurasian tree sparrow positively; eurasian tree sparrow correlated negatively with VEG250 (figure 2). This indicates that different bird species respond differently to environmental changes.

\subsubsection{Variables that affect avian richness and abundance}

As table 4 indicates, 3 variables, including park area (AREA), percentage of area covered by water (WATER\%), and building area (at $\mathrm{R}=2000 \mathrm{~m}$ scale, BUILD2000) surrounding the park, out of the 12 were chosen in the regression models. AREA, explain $64 \%$ of the variations, is the most important variable affecting the avian species richness. The largest park had more than twice as many species as did the smallest park. WATER\% also affected species richness positively; adding this factor in the regression model increased the amount of variation explained by $17.4 \%$ and $14.7 \%$, respectively.

The increasing degree of urbanization, measured by the number of building area surround the park, increased the abundance of birds observed in the park, and reduced the diversity index. Regarding individual species, eurasian tree sparrow, rock pigeon correlated positively with BUILD2000, and brown shrike negatively (figure 2). However, the adj_R2 value of the abundance regression model is only 0.233 , indicating that there is still $76.7 \%$ of the variation unexplained.

\section{Conclusions}

Owing to the low density and limited observation, to ascertain which environmental variable affect the rarely seen birds is difficult. However, we found that rarely seen birds (observed in less than 2 parks) occurred in either the largest park or the park surrounded by large vegetation covered area. And the increasing degree of urbanization tends to decrease the occurrence of rarely seen birds, and increase urban common species, such as eurasian tree sparrow, and rock pigeon.

The result of our study demonstrated that wide scales of urban environmental variables, including the building area and vegetation covered area, significantly affect avian composition. In addition, the main factor influencing the avian species richness is the park area. Therefore, in order to increase the avian richness, we should increase the park area as much as possible. To attract more species, the land use around the park should also be considered. 


\section{Appendix A}

\begin{tabular}{|c|c|c|c|}
\hline Common name & Scientific name & $\begin{array}{l}\text { Total } \\
\text { counts }\end{array}$ & $\begin{array}{l}\text { Number of } \\
\text { parks } \\
\text { occurred in }\end{array}$ \\
\hline eurasian tree sparrow & Passer montanus & 1535 & 17 \\
\hline light-vented bulbul & Pycnonotus sinesis & 2389 & 17 \\
\hline Japanese White-eye & Zosterops japonica & 1631 & 17 \\
\hline barn swallow & Hirundo rustica & 60 & 13 \\
\hline pacific swallow & Hirundo tahitica & 207 & 17 \\
\hline house swift & Apus affinis & 33 & 11 \\
\hline spotted dove & Streptopelia chinesis & 100 & 14 \\
\hline red-collared dove & Streptopelia tranquebarica & 132 & 11 \\
\hline rock pigeon & Columbia livia & 259 & 5 \\
\hline grey treepie & Crypsirina formosae & 42 & 9 \\
\hline black-naped monarch & Hypothymis azurea & 56 & 9 \\
\hline black drongo & Ddicrurus macrocercus & 24 & 2 \\
\hline black-billed magpie & Pica pica & 94 & 4 \\
\hline crested myna & Acridotheres cristatellus & 15 & 6 \\
\hline brown shrike & Lanius cristatus & 215 & 16 \\
\hline crested goshawk & Accipiter trivirgatus & 4 & 1 \\
\hline $\begin{array}{l}\text { black-crowned night } \\
\text { heron }\end{array}$ & Nycticorax nycticorax & 22 & 1 \\
\hline little egret & Egretta garzetta & 7 & 2 \\
\hline common teal & Anas crecca & 13 & 1 \\
\hline scaly-breasted Munia & Lonchura punctulata & 103 & 3 \\
\hline plain prinia & Prinis subflava & 5 & 2 \\
\hline grey-cheeked fulvetta & Alcippe morrisonia & 15 & 3 \\
\hline common kingfisher & Alcedo atthis & 4 & 2 \\
\hline scaly-breasted munia & Turdus pallidus & 2 & 1 \\
\hline pigmy woodpecker & Dendrocopos canicapillus & 6 & 1 \\
\hline black-headed shrike & Lanius schach & 3 & 1 \\
\hline dauruan redstart & Phoenicurus auroreus & 1 & 1 \\
\hline
\end{tabular}




\section{References}

[1] Beissinger S. R., Osborne D. R., 1982, "Effects of urbanization on avian community organization" Condor, 84:75-83

[2] Blair R. B., 1996, "Land use and avian species diversity along an urban gradient" Ecological Applications, 6(2): 506-519

[3] Carlson T. N., Ripley D. A., 1997, On the relation between NDVI, fractional vegetation cover, and leaf area index, Remote Sensing of Environment, 62:241-252

[4] Clarke K. R. and Gorley R. N., 2001, <PRIMER v5: User Manual Tutorial.> Primer-e, Plymouth Marine Laboratory. Plymouth, UK

[5] Clarke K. R., Warwick R. M., 2001, Changes in Marine Community: An Approach to Statistical Analysis and Interpretation. PRIMER-R, Plymouth, UK

[6] Emlen J. T., 1974, "an urban bird community in tuscon, arizona: derivation, structure, regulation" Condor, 76:194-197

[7] Fernández-Juricic E., Jimenez M. D., Lucas E., 2001, < Bird tolerance to human disturbance in urban parks of Madrid (Spain): Management implications. In: Marzuluff J. M., Bowman R., Donnelly R. editors Avian ecology and conservation in an urbanizing world $>$ Kluwer Academic Publishers

[8] Gould W., 2000, "remote sensing of vegetation, plant species richness, and regional bidiversity hotspots" Ecological Applications, 10(6):1861-1870

[9] Hostetler M., Holling C. S., 2000, "Detecting the scales at which birds respond to structure in urban landscape" Urban Ecosystem, 4:25-54

[10] Lim H. C., Sodhi N. S., 2004, "Responses of avian guilds to urbanisation in a tropical city" Landscape and Urban Planning, 66:199-21

[11] Lillesand T. M., Kiefer R. W., Chipman J. W., 2004, <Remote Sensing and Image Interpretation $>$ John Wiley \& Sons Inc.

[12] McDonnell M. J., Pickett S. T. A., Groffman P., Bohlen P., Pouyat R. V., Zipperer W. C., Parmelee R. W., Carreiro M. M., Medley K., 1997, "Ecosystem process along an urban-to-rural gradient" Urban Ecosystems, $1: 21-36$

[13] Nohr H., Jorgensen A. F., 1997, "mapping of biological diversity in Sahel by means of satellite image analyses and ornithological surveys" Biodiversity and Conservation 6:545-566

[14] Seto K. C., Fleishman E., Fay J. P., Retrus C. J., 2004, Linking spatial patterns of bird and butterfly species richness with Landsat TM derived NDVI, International Journal of Remote Sensing, 25:4309-4324

[15] Tilghman N. G., 1987, "Characteristics of urban woodlands affecting breeding bird diversity and abundance" Landscape and Urban Planning, 14:481-495

[16] Tucker C. J., Vanpraet C. L., Boerwinkel E., Gaston A., 1983, Satellite remote sensing of total dry matter production in the Senegalese Sahel: 1980-1984, Remote Sensing of Environment, 17:233-249 